Check for updates

Cite this: New J. Chem., 2019, 43, 13741

Received 2nd July 2019,

Accepted 7th August 2019

DOI: 10.1039/c9nj03426a

rsc.li/njc

\section{Solution versus solid-state dual emission of the Au(I)-alkynyl diphosphine complexes via modification of polyaromatic spacers $\dagger$}

\author{
Andrey Belyaev, (D)*a Ilya Kolesnikov, ${ }^{b}$ Alexei S. Melnikov, ${ }^{c}$ Vladislav V. Gurzhiy, (DD d \\ Sergey P. Tunik (D) ${ }^{e}$ and Igor O. Koshevoy (iD *a
}

\begin{abstract}
Single molecule luminophores capable of multiple emissions are essential for the development of new materials with unconventional photophysical behavior. In this work, a family of diphosphine ligands $\mathrm{PPh}_{2}-\mathrm{PAH}-\mathrm{PPh}_{2}$ with variable polyaromatic hydrocarbon (PAH) spacers (PAH = 9,10-anthracene L1, 1,4-naphthalene L2, 2,6-naphthalene L3, and their diethynyl congeners L4-L6) were employed to prepare gold(I) complexes $\left(\mathrm{RC}_{2} \mathrm{Au}\right) \mathrm{PPh}_{2}-\mathrm{PAH}-\mathrm{PPh}_{2}\left(\mathrm{AuC}_{2} \mathrm{R}\right)(\mathbf{1 - 2 2})$, containing a selection of alkynyl groups. Investigation of their optical properties indicates that compounds with anthracene-based diphosphines (1-4 and 13-16) display only ${ }^{1} \mathrm{IL}\left(\pi \pi^{\star}\right)$ fluorescence with $\Phi_{\mathrm{em}}$ up to $93 \%$. The naphthalene and diethynyl-naphthalene diphosphine complexes (5-12 and 17-22), however, demonstrate panchromatic emission in the solid state and in solution featuring well-separated low and high energy signals, which originate from ${ }^{1} \mathrm{IL}\left(\pi \pi^{\star}\right)$ and ${ }^{3} \mathrm{IL}\left(\pi \pi^{\star}\right)$ transitions along with certain contribution from metal to ligand and ligand to ligand charge transfers.
\end{abstract}

\section{Introduction}

The nature of the ground and excited states of luminescent molecules primarily determines their photophysical characteristics, such as absorption and emission, the rates of radiative and nonradiative processes and, consequently, the excited state lifetimes. Rational design of the emitting molecular skeleton is expected to provide control over the energies of electronic transitions by manipulating the Frontier molecular orbitals. Such target modulation of luminescence properties results in solvatochromism, thermally activated delayed fluorescence, stimuli-responsive behavior, long-lived phosphorescence, and panchromatic emission, which are suitable for a number of practical applications including electroluminescent devices, sensors and bioimaging. ${ }^{1,2}$

One approach to novel light emitting materials involves the incorporation of late transition metal atoms $\left(\mathrm{Os}^{\mathrm{II}}, \mathrm{Re}^{\mathrm{I}}, \mathrm{Ir}^{\mathrm{III}}\right.$,

\footnotetext{
${ }^{a}$ Department of Chemistry, University of Eastern Finland, Joensuu, 80101, Finland. E-mail: andreib@uef.fi, igor.koshevoy@uef.fi

${ }^{b}$ Center for Optical and Laser Materials Research, St. Petersburg State University, St. Petersburg, 198504, Russia

${ }^{c}$ St. Petersburg State Polytechnical University, St. Petersburg, 195251, Russia

${ }^{d}$ Crystallography Department, St. Petersburg State University, St. Petersburg, 198504, Russia

${ }^{e}$ Institute of Chemistry, St. Petersburg State University, St. Petersburg, 198504, Russia

† Electronic supplementary information (ESI) available. CCDC 993387-993389, 1054718-1054720, 1937321 and 1937322. For ESI and crystallographic data in CIF or other electronic format see DOI: 10.1039/c9nj03426a
}

$\mathrm{Pt}^{\mathrm{II}}$ and $\mathrm{Au}^{\mathrm{I} / \mathrm{III}}$ ) into an organic chromophore. ${ }^{3}$ In particular, the formation of the $\sigma$-bond between the carbon skeleton and the gold(I) ion by means of a heavy atom effect enhances spinorbit coupling (SOC) and accelerates the rate of intersystem crossing (ISC, i.e. singlet-triplet transition $\mathrm{S}_{1} \rightarrow \mathrm{T}_{1}$ ). This leads to a rapid population of the triplet excited state and further can induce "forbidden" phosphorescence $\left(\mathrm{T}_{1} \rightarrow \mathrm{S}_{0}\right)$. However, the reports of pure room temperature fluorescence $\left(S_{1} \rightarrow S_{0}\right)$ from the molecules containing gold atoms indicate that the presence of this heavy element does not necessarily ensure a fast ISC rate, and the nature of the ligands also plays an important role in the excited-state dynamics and deactivation mechanisms. ${ }^{3 a, 4}$ Conversely, in the case of moderate ISC rate constant, compatible with that of fluorescence relaxation, room temperature fluorescence/phosphorescence dual emission $\left(S_{1}+T_{1} \rightarrow S_{0}\right)$ can be observed for this sort of gold compound. Construction of such emitters remains a challenge due to the need to keep a delicate balance of populating the $S_{1}$ and $T_{1}$ excited states, but potential benefits of this photophysical phenomenon comprise ratiometric oxygen and $\mathrm{pH}$ monitoring, ${ }^{5}$ white-light generation, ${ }^{5 b, 6}$ and fluorescence/phosphorescence lifetime imaging. ${ }^{7}$

Dually emissive gold(I) organometallic species predominantly have low nuclearity and belong to the well-studied LAuX type with a linear two-coordinate geometry of the metal center. These complexes are conventionally composed of isolobal to the proton $\mathrm{LAu}^{+}\left(\mathrm{L}=\right.$ phosphine or N-heterocyclic carbene) cationic fragments, ${ }^{8}$ which are complemented by $\sigma$-bonded aromatic, ${ }^{4 c, 9}$ alkynyl, ${ }^{10}$ or halide ${ }^{11} \mathrm{X}$ ligands. Among accessible variations of the 
$A$

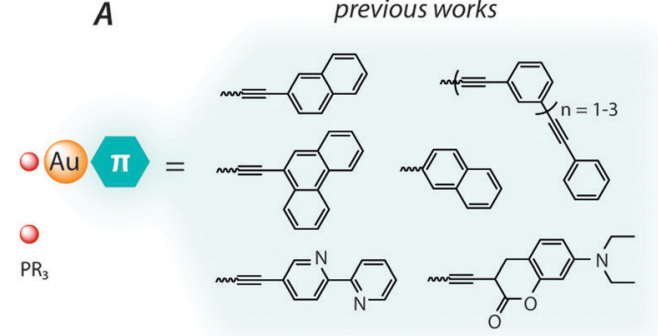

B

Au-chromophore distance dependent $\mathrm{Fl} / \mathrm{Ph}$ ratio
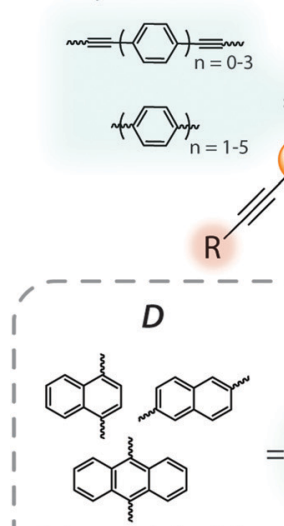

I solution state dual-emission

1

1

1

Fig. 1 The representative families of previously studied dually emissive phosphine-gold(I) alkynyl complexes $(A-C)$, and the scope of the current work (D).

constituents, phosphine-alkynyl complexes $\left(\mathrm{R}_{3} \mathrm{PAu}-\mathrm{C} \equiv \mathrm{C}\right)_{n}-\mathrm{R}^{\prime}$ prevail in the family of dual gold(I) luminophores due to facile synthesis and functionalization (Fig. 1A). Their photophysical properties are mainly regulated by intraligand transitions localized on the alkynyl ligands, which may contain a wide range of conjugated organic groups. As a representative illustration, simultaneous ligand-centered dual fluorescence (prompt and delayed) and phosphorescence of the conjugated (poly)phenylethylene-gold(I) phosphine complexes was described by the group of Che. ${ }^{10 a}$ Another molecular design, which is less common, implies the incorporation of a $\pi$-chromophore spacer into the diphosphine moiety. Utilizing this strategy, we reported a series of dinuclear gold(I) alkynyl complexes based on oligophenylene diphosphine ligands. The rate of ISC for these compounds systematically decreases upon an increase of the effective distance between the heavy gold atom and the center of the chromophore fragment, which allows for fine-tuning the fluorescence/phosphorescence ratio by varying the length of the oligophenylene spacer (Fig. 1B). ${ }^{6 a, 12}$ Moreover, the electronic properties of the ancillary alkynyl substituents (Fig. 1C) were shown to affect significantly the rate of the ISC process by means of altering the contribution of charge transfer transitions, and therefore influence the probability of singlet $v s$. triplet emission. ${ }^{13}$

In the continuation of our studies, herein, we employ a family of diphosphine ligands based on the polyaromatic spacers (anthracene, naphthalene and their diethynyl derivatives, Fig. 1D). These P-donor modified chromophores were utilized for the preparation of novel gold(I) alkynyl complexes, the luminescence behavior of which was analyzed in solution and in the solid state to correlate with their molecular structures.

\section{Experimental section}

\section{General comments}

9,10-Bis-(diphenylphosphino)anthracene $(\mathbf{L 1}){ }^{4 a} \quad\left(\mathrm{AuC}_{2} \mathrm{CR}\right)_{n}$ $\left(\mathrm{R}=\mathrm{Ph} ; 4-\mathrm{C}_{6} \mathrm{H}_{4}-\mathrm{X}, \mathrm{X}=\mathrm{CF}_{3}, \mathrm{OMe}, \mathrm{NH}_{2}, \mathrm{NMe}_{2}, \mathrm{Ph} ; \mathrm{C}\left(\mathrm{CH}_{3}\right)_{2} \mathrm{OH}\right.$; $\left.\mathrm{C}_{6} \mathrm{H}_{10} \mathrm{OH} ; \mathrm{C}_{(}\left(\mathrm{C}_{6} \mathrm{H}_{5}\right)_{2} \mathrm{OH}\right),{ }^{14}$ and diethynylarenes (arene $=9,10$ anthracene; 1,4- and 2,6-naphthalene) ${ }^{15}$ were synthesized according to the published procedures. Tetrahydrofuran (THF) and diethyl ether were distilled over Na-benzophenone ketyl under a nitrogen atmosphere prior to use. Other reagents and solvents were used as received. The solution ${ }^{1} \mathrm{H},{ }^{31} \mathrm{P}\left\{{ }^{1} \mathrm{H}\right\}$ and ${ }^{1} \mathrm{H}-{ }^{1} \mathrm{H}$ COSY NMR spectra were recorded on a Bruker 400 Avance spectrometer. Mass spectra were recorded with a Bruker maXis HD ESI-QTOF instrument in the $\mathrm{ESI}^{+}$mode. Microanalyses were carried out in the analytical laboratories of the University of Eastern Finland and of Saint-Petersburg State University.

\section{Photophysical measurements}

Absorption spectra were recorded using Lambda 1050 and Shimadzu UV 1800 spectrophotometers; excitation and emission spectra in solution and the solid-state were measured on Fluoromax 4 and Fluorolog 3 spectrofluorimeters. LEDs (maximum of emission at $265 \mathrm{~nm}, 340 \mathrm{~nm}$ and $390 \mathrm{~nm}$ ) were used in the pulse mode to pump luminescence in fluorescence lifetime measurements (pulse width $\sim 1$ ns and repetition rate $100 \mathrm{MHz}$ to $10 \mathrm{kHz}$ ). DTL-399QT Laser-export Co. Ltd (351 nm, $50 \mathrm{~mW}$, pulse width $6 \mathrm{~ns}$ and repetition rate $0.01-1 \mathrm{kHz}$ ), MUM monochromator (LOMO, $1 \mathrm{~nm}$ bandwidth), counting head for photons H10682 (Hamamatsu) and digital time transducer P7887 (FAST ComTec GmbH) were used to measure the phosphorescence lifetime. The emission quantum yield in solution was determined by Vavilov's method ${ }^{16}$ using LED $(385 \mathrm{~nm}$, continuous mode) and xenon lamp pumping, with coumarine $102\left(\Phi_{\mathrm{em}}=0.76\right)$ and tryptophan $\left(\Phi_{\mathrm{em}}=0.13\right)$ as standards. The solutions were carefully degassed by purging Ar for $25 \mathrm{~min}$. The integration sphere Quanta- $\varphi$ (6-inches) was used to measure the solid state emission quantum yields for the complexes by an absolute method.

1,4-Bis-(diphenylphosphino)naphthalene (L2). A 1.6 M solution of $n$-BuLi in hexanes ( $2.8 \mathrm{ml}, 4.5 \mathrm{mmol})$ was added dropwise to a solution of 1,4-dibromonaphthalene $(0.65 \mathrm{~g}, 2.3 \mathrm{mmol})$ in diethyl ether $(45 \mathrm{ml})$ at $0{ }^{\circ} \mathrm{C}$. The resulting suspension was stirred at this temperature for $30 \mathrm{~min}$ and then allowed to reach room temperature. It was stirred for an additional hour, then was treated dropwise with neat $\mathrm{PPh}_{2} \mathrm{Cl}(1.04 \mathrm{~g}, 4.7 \mathrm{mmol})$. Stirring was continued for 3 hours and then the reaction was quenched with a saturated aqueous solution of $\mathrm{NH}_{4} \mathrm{Cl}(30 \mathrm{ml})$. Dichloromethane $(30 \mathrm{ml})$ was added to dissolve organic solids. The layers were separated and the aqueous layer was further extracted with 
dichloromethane $(3 \times 20 \mathrm{ml})$. The combined organics were dried over $\mathrm{Na}_{2} \mathrm{SO}_{4}$, filtered and evaporated. The resulting yellow oil was purified by column chromatography (silica gel, 150 mesh, $2.5 \times 15 \mathrm{~cm}$, eluent $\mathrm{CH}_{2} \mathrm{Cl}_{2} /$ hexanes $1: 4 \mathrm{v} / \mathrm{v}$ ) and further recrystallized by slow evaporation of a hexanes $/ \mathrm{CH}_{2} \mathrm{Cl}_{2}$ solution of $\mathbf{L} 2$ at $+5{ }^{\circ} \mathrm{C}$ to afford a colorless crystalline material $(0.62 \mathrm{~g}$, 55\%). ${ }^{31} \mathrm{P}\left\{{ }^{1} \mathrm{H}\right\}$ NMR $\left(\mathrm{CDCl}_{3}, 298 \mathrm{~K} ; \delta\right):-13.4(\mathrm{~s}) .{ }^{1} \mathrm{H}$ NMR $\left(\mathrm{CDCl}_{3}\right.$, $298 \mathrm{~K} ; \delta$ ): 8.45-8.48 (m, 3,6- $\left.\mathrm{H} \mathrm{C}_{10} \mathrm{H}_{6}, 2 \mathrm{H}\right), 7.44-7.48(\mathrm{~m}, 4,5-\mathrm{H}$ $\left.\mathrm{C}_{10} \mathrm{H}_{6}, 2 \mathrm{H}\right), 7.30-7.36(\mathrm{~m}, \mathrm{Ph}, 20 \mathrm{H}), 6.86-6.87$ (m, 1,2- $\left.\mathrm{H} \mathrm{C}_{10} \mathrm{H}_{6}, 2 \mathrm{H}\right)$. Anal. calc. for $\mathrm{C}_{34} \mathrm{H}_{26} \mathrm{P}_{2}$ : C, 82.25; H, 5.28. Found: C 81.98; H 5.34.

2,6-Bis-(diphenylphosphino)naphthalene (L3). L3 was prepared analogously to $\mathbf{L 2}$ from 2,6-dibromonaphthalene $(1.00 \mathrm{~g}$, $3.5 \mathrm{mmol}$ ). Recrystallization by gas-phase diffusion of diethyl ether into a dichloromethane solution of $\mathbf{L 3}$ at $+5{ }^{\circ} \mathrm{C}$ afforded a colorless crystalline material (1.08 g, 62\%). ${ }^{31} \mathrm{P}\left\{{ }^{1} \mathrm{H}\right\}$ NMR $\left(\mathrm{CDCl}_{3}, 298 \mathrm{~K} ; \delta\right):-4.7$ (s). ${ }^{1} \mathrm{H}$ NMR $\left(\mathrm{CDCl}_{3}, 298 \mathrm{~K} ; \delta\right): 7.75$ (d, $\left.{ }^{3} J_{\mathrm{HH}} 8.4,3,6-\mathrm{H} \mathrm{C}_{10} \mathrm{H}_{6}, 2 \mathrm{H}\right), 7.68\left(\mathrm{~d},{ }^{3} J_{\mathrm{HH}} 8.4 \mathrm{~Hz}, 2,5-\mathrm{H} \mathrm{C}_{10} \mathrm{H}_{6}\right.$, $2 \mathrm{H}$ ), 7.4-7.35 (m, $\mathrm{Ph}$ and $\left.1,4-\mathrm{H} \mathrm{C}_{10} \mathrm{H}_{6}, 22 \mathrm{H}\right)$. Anal. calc. for $\mathrm{C}_{34} \mathrm{H}_{26} \mathrm{P}_{2}$ : C, 82.25; H, 5.28. Found: C, 82.30; H, 5.30.

9,10-Bis-[(diphenylphosphino)ethynyl] anthracene (L4). 9,10Diethynyl anthracene $(0.75 \mathrm{~g}, 3.3 \mathrm{mmol})$ was suspended in THF $(50 \mathrm{ml})$ and cooled to $-78{ }^{\circ} \mathrm{C}$. A $1.6 \mathrm{M}$ solution of $n$-BuLi in hexanes $(4.4 \mathrm{ml}, 7.0 \mathrm{mmol})$ was slowly added dropwise. The reaction mixture was warmed to $-30{ }^{\circ} \mathrm{C}$ within $c a .1 \mathrm{~h}$, then cooled to $-78{ }^{\circ} \mathrm{C}$ again and treated dropwise with neat $\mathrm{PPh}_{2} \mathrm{Cl}$ $(1.52 \mathrm{~g}, 6.9 \mathrm{mmol})$. The reaction mixture was allowed to reach room temperature and was stirred overnight. Then the solvents were evaporated, and the solid residue was washed with methanol $(3 \times 20 \mathrm{ml})$ and vacuum dried. Crude $\mathbf{L 4}$ was passed through a silica gel (150 mesh, $2.5 \times 15 \mathrm{~cm}$, eluent $\mathrm{CH}_{2} \mathrm{Cl}_{2} /$ hexanes $\left.1: 1 \mathrm{v} / \mathrm{v}\right)$. The pure sample was obtained by additional treatment of $\mathbf{L A}$ with activated charcoal in dichloromethane and recrystallization by slow evaporation of a toluene/ $\mathrm{CH}_{2} \mathrm{Cl}_{2}$ solution of $\mathbf{L 4}$ at $+5{ }^{\circ} \mathrm{C}$ to afford bright yellow needles $(1.24 \mathrm{~g}, 63 \%) .{ }^{31} \mathrm{P}\left\{{ }^{1} \mathrm{H}\right\}$ NMR $\left(\mathrm{CDCl}_{3}\right.$, $298 \mathrm{~K} ; \delta):-32.7(\mathrm{~s}) .{ }^{1} \mathrm{H}$ NMR $\left(\mathrm{CDCl}_{3}, 298 \mathrm{~K} ; \delta\right): 8.55-8.57$ (m, 1,4,5,8- $\left.\mathrm{H} \mathrm{C}_{14} \mathrm{H}_{8}, 4 \mathrm{H}\right), 7.81-7.85$ (m, ortho- $\mathrm{H} \mathrm{Ph,} \mathrm{8H),} \mathrm{7.57-7.59}$ $\left(\mathrm{m}, 2,3,6,7-\mathrm{H} \mathrm{C}_{14} \mathrm{H}_{8}, 4 \mathrm{H}\right), 7.41-7.47$ (m, meta + para $\left.-\mathrm{H} \mathrm{Ph}, 12 \mathrm{H}\right)$. Anal. calc. for $\mathrm{C}_{42} \mathrm{H}_{28} \mathrm{P}_{2}$ : C, 84.84; H, 4.75. Found: C, 84.64; H, 4.81 .
1,4-Bis-[(diphenylphosphino)ethynyl]naphthalene (L5). L5 was prepared analogously to $\mathbf{L} \mathbf{4}$ from 1,4-diethynylnaphthalene $(0.60 \mathrm{~g}, 3.4 \mathrm{mmol})$. Recrystallization by gas-phase diffusion of diethyl ether into a dichloromethane solution of $\mathbf{L 5}$ at $+5{ }^{\circ} \mathbf{C}$ afforded a colorless crystalline material (1.34 g, 73\%). ${ }^{31} \mathrm{P}\left\{{ }^{1} \mathrm{H}\right\}$ $\mathrm{NMR}\left(\mathrm{CDCl}_{3}, 298 \mathrm{~K} ; \delta\right):-33.3(\mathrm{~s}) .{ }^{1} \mathrm{H} \mathrm{NMR}\left(\mathrm{CDCl}_{3}, 298 \mathrm{~K} ; \delta\right): 8.35-$ $8.37\left(\mathrm{~m}, 2,5-\mathrm{H} \mathrm{C}_{10} \mathrm{H}_{6}, 2 \mathrm{H}\right), 7.73-7.78(\mathrm{~m}$, ortho- $\mathrm{H} \mathrm{Ph}$ and 3,6- $\mathrm{H}$ $\mathrm{C}_{10} \mathrm{H}_{6}, 10 \mathrm{H}$ ), 7.59-7.61 (m, 3,4- $\left.\mathrm{H} \mathrm{C}_{10} \mathrm{H}_{6}, 2 \mathrm{H}\right)$, 7.39-7.44 (m, meta + para- $\mathrm{H} \mathrm{Ph}, 12 \mathrm{H})$. Anal. calc. for $\mathrm{C}_{38} \mathrm{H}_{26} \mathrm{P}_{2}$ : C, 83.81; $\mathrm{H}, 4.81$. Found: C, 83.61; H, 4.75.

2,6-Bis-[(diphenylphosphino)ethynyl]naphthalene (L6). L6 was prepared analogously to L4 from 2,6-diethynylnaphthalene $(0.60 \mathrm{~g}, 3.4 \mathrm{mmol})$. Recrystallization by slow evaporation of a methanol $/ \mathrm{CH}_{2} \mathrm{Cl}_{2}$ solution of $\mathbf{L 6}$ at $+5{ }^{\circ} \mathrm{C}$ afforded a light yellow crystalline material (1.13 g, 61\%). ${ }^{31} \mathrm{P}\left\{{ }^{1} \mathrm{H}\right\} \mathrm{NMR}\left(\mathrm{CDCl}_{3}, 298 \mathrm{~K} ; \delta\right)$ : -33.7 (s). ${ }^{1} \mathrm{H}$ NMR $\left(\mathrm{CDCl}_{3}, 298 \mathrm{~K} ; \delta\right): 8.04$ (s, 1,4-H $\left.\mathrm{C}_{10} \mathrm{H}_{6}, 2 \mathrm{H}\right)$, $7.78\left(\mathrm{~d},{ }^{3} \mathrm{~J}_{\mathrm{HH}} 8.4 \mathrm{~Hz}, 3,6-\mathrm{H} \mathrm{C}_{10} \mathrm{H}_{6}, 2 \mathrm{H}\right), 7.69-7.74$ (m, ortho- $\left.\mathrm{H} \mathrm{Ph}, 8 \mathrm{H}\right)$, $7.60\left(\mathrm{~d},{ }^{3} J_{\mathrm{HH}} 8.4 \mathrm{~Hz}, 2,5-\mathrm{H} \mathrm{C}_{10} \mathrm{H}_{6}, 2 \mathrm{H}\right), 7.37-7.42$ (m, meta, para- $\mathrm{H}$ $\mathrm{Ph}, 12 \mathrm{H}$ ). Anal. calc. for $\mathrm{C}_{38} \mathrm{H}_{26} \mathrm{P}_{2}$ : C, 83.81; H, 4.81. Found: C, 83.54; $\mathrm{H}, 4.80$.

\section{General procedure for the preparation of complexes 1-22}

$\left(\mathrm{AuC}_{2} \mathrm{R}\right)_{n}(0.3 \mathrm{mmol})$ was mixed with the corresponding diphosphine $(0.16 \mathrm{mmol})$ in dichloromethane $(10 \mathrm{ml})$. The reaction mixture was stirred for $45 \mathrm{~min}$ in the absence of light. The resulting solution was filtered through a Celite pad and vacuum dried and the solid residue was purified by recrystallization. The crystallization and spectroscopic details are given in the ESI. $\dagger$

\section{Results and discussion}

\section{Synthesis and characterization}

Two families of diphosphine ligands containing polyaromatic hydrocarbon (PAH) backbones (9,10-anthracene (L1), 1,4-naphthalene (L2), 2,6-naphthalene (L3), and their PAH-diethynyl congeners (L4-L6), Scheme 1) were conventionally prepared in good yields via lithiation of dihalo- or diethynyl PAH precursors and

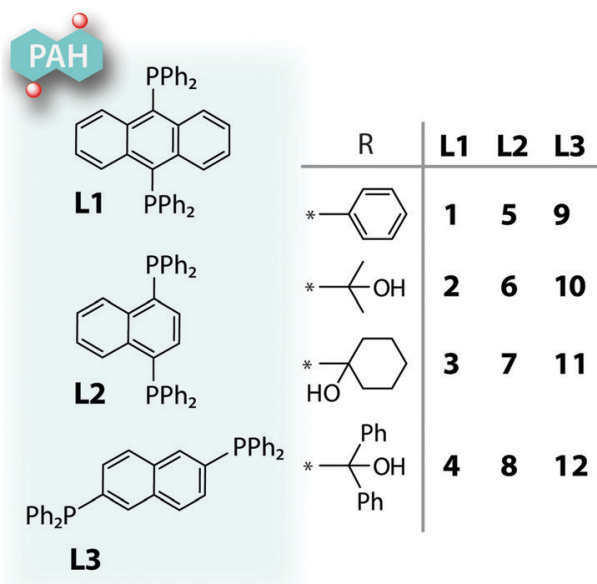

Scheme 1 Polyaromatic phosphine ligands and their gold(ı) alkynyl complexes 1-22.
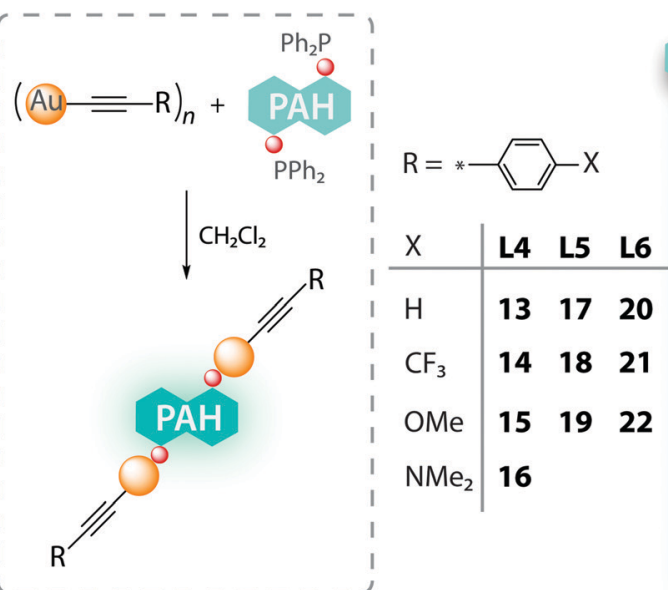

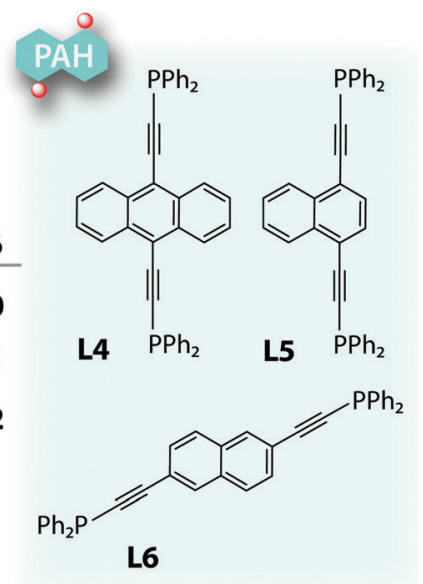


coupling the metalated derivatives with a stoichiometric amount of $\mathrm{PPh}_{2} \mathrm{Cl}$.

The dinuclear complexes $\left(\mathrm{RC}_{2} \mathrm{Au}\right) \mathrm{PPh}_{2}-\mathrm{spacer}-\mathrm{PPh}_{2}\left(\mathrm{AuC}_{2} \mathrm{R}\right)$ were readily obtained by reacting $\left(\mathrm{AuC}_{2} \mathrm{R}\right)_{n}$ species with the corresponding bidentate ligands under ambient conditions (Scheme 1), analogously to a number of earlier reported congener species. ${ }^{13,14,17}$ The resulting compounds form two series (1-12) and (13-22), which are distinguished by the type of stereochemically and electronically different phosphine ligands (tertiary aromatic L1-L3 and ethynyl-aromatic L4-L6, respectively).

In solution, all the title complexes 1-22 were characterized using $\mathrm{ESI}^{+}$mass spectrometry and ${ }^{1} \mathrm{H}$ and ${ }^{31} \mathrm{P}$ NMR spectroscopy. The ESI MS spectrum of 1-12 (Fig. S1, ESI $\dagger$ ) shows the dominating signals of positively charged ion signals generated

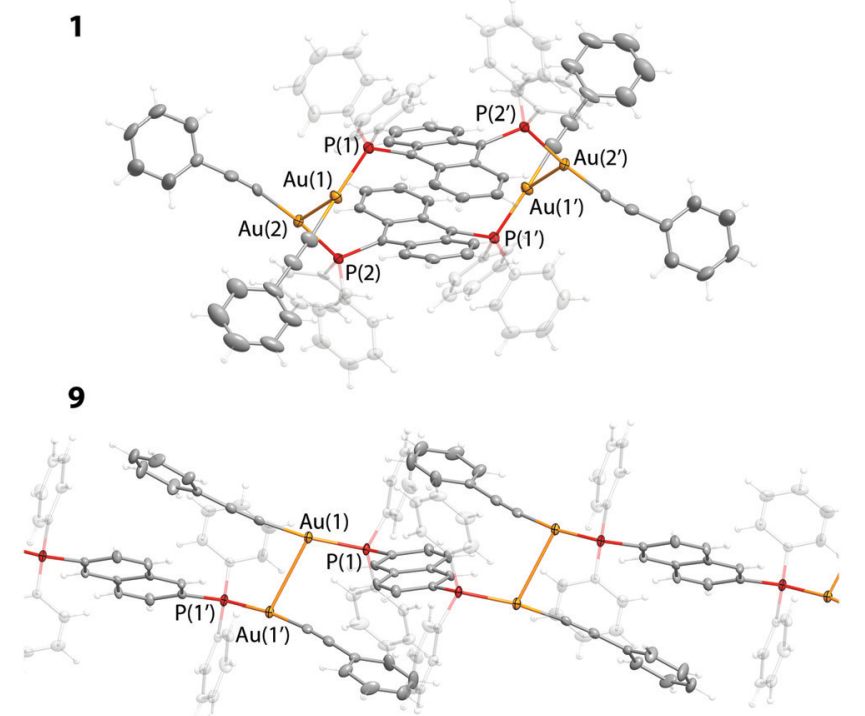

Fig. 2 Molecular views of dimer $\mathbf{1}$ and polymer $\mathbf{9}$ (thermal ellipsoids are shown at $50 \%$ probability). either by dissociation of alkynyl ligands or by association of the corresponding molecules with $\mathrm{Na}^{+}$ions. The ${ }^{31} \mathrm{P}\left\{{ }^{1} \mathrm{H}\right\}$ NMR spectra of 1-22 display singlet resonances with chemical shifts in the ranges of 36.3-43.0 ppm (1-12) and 16.4-17.1 ppm (13-22), which are typical for the gold(I) compounds containing the related phosphines ${ }^{13}$ and are virtually insensitive to the nature of alkynyl ligands. These data indicate that complexes 1-22 exist in solution in their molecular forms of idealized symmetry that is additionally supported by the ${ }^{1} \mathrm{H}$ NMR spectroscopic patterns, completely compatible with molecular arrangements shown in Scheme 1.

The solid-state structures of 1-3, 7, 9, 12, 13 and 19 have been elucidated by the XRD analysis (Fig. 1-4 and Fig. S2, ESI $\dagger$ ); selected structural parameters are summarized in Table S2 (ESI $\dagger$ ). Complexes 1 and 9 containing $-\mathrm{C}_{2} \mathrm{Ph}$ ligands display intermolecular $\mathrm{Au}-\mathrm{Au}$ interactions to form a dimeric structure and an infinite polymeric structure.

The metal-metal distances in 1 (3.092 $\AA$ ) and 9 (3.212 $\AA$ ) are typical for aurophilic bonding frequently encountered in the crystals of gold(I) phosphine compounds. ${ }^{18}$

The Au(I) species with hydroxyaliphatic alkynes (2, 3, 7 and 12) do not feature metallophilic contacts (Fig. 3 and Fig. S2, ESI $\dagger$ ). Alternatively, complexes $\mathbf{2}$ and $\mathbf{3}$ with anthracene diphosphine $\mathbf{L 1}$ demonstrate extensive intermolecular $\mathrm{O}-\mathrm{H} \cdots$ O hydrogen bonding (O. . O separations are 2.76-2.88 $\mathrm{A}$ ) that evidently affects molecular packing for these species (Fig. S2 and S3, ESI $\dagger$ ). The visible bending of anthracene motifs in 1-3 is similar to that observed for other gold compounds based on $\mathbf{L 1}$, and has been tentatively attributed to intramolecular steric hindrance. ${ }^{4 a, 19}$

\section{Photophysical properties}

Complexes 1-4. The absorption and emission spectra of 1-4 are shown in Fig. 5, while the corresponding data are given in Table 1. These complexes display similar absorption spectra which are nearly identical to those of the free diphosphine ligand $\mathbf{L 1}$ and its reported gold(I) compounds. ${ }^{4 a, 19 b}$ Analogously to a previous analysis, intense high energy (270 $\mathrm{nm}$ ) and low energy

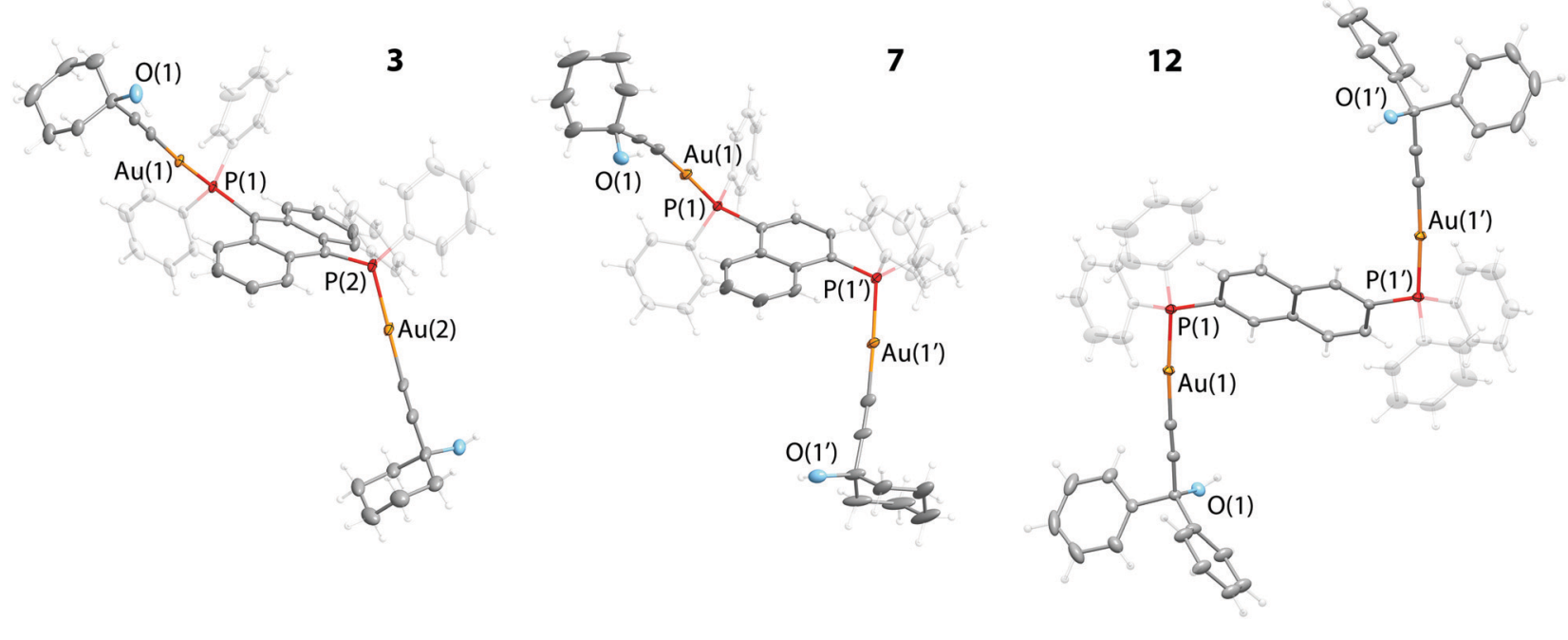

Fig. 3 Molecular views of complexes 3, 7 and $\mathbf{1 2}$ (thermal ellipsoids are shown at 50\% probability). 
13

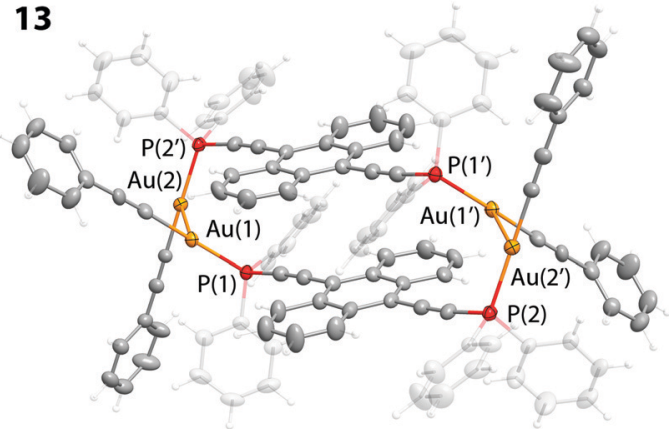

$\log _{2}$

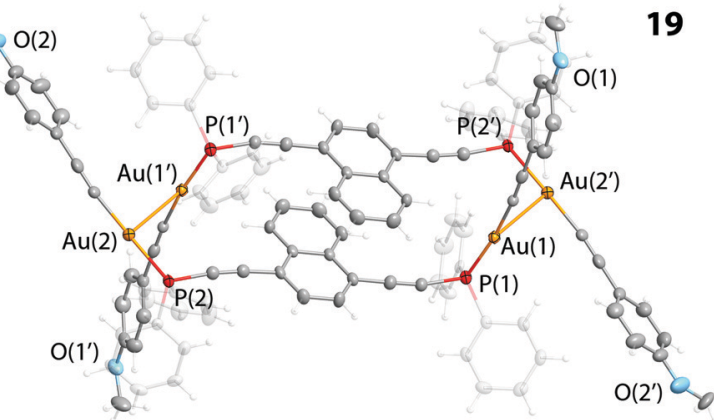

Fig. 4 Molecular views of dimers 13 and 19 (thermal ellipsoids are shown at $50 \%$ probability).
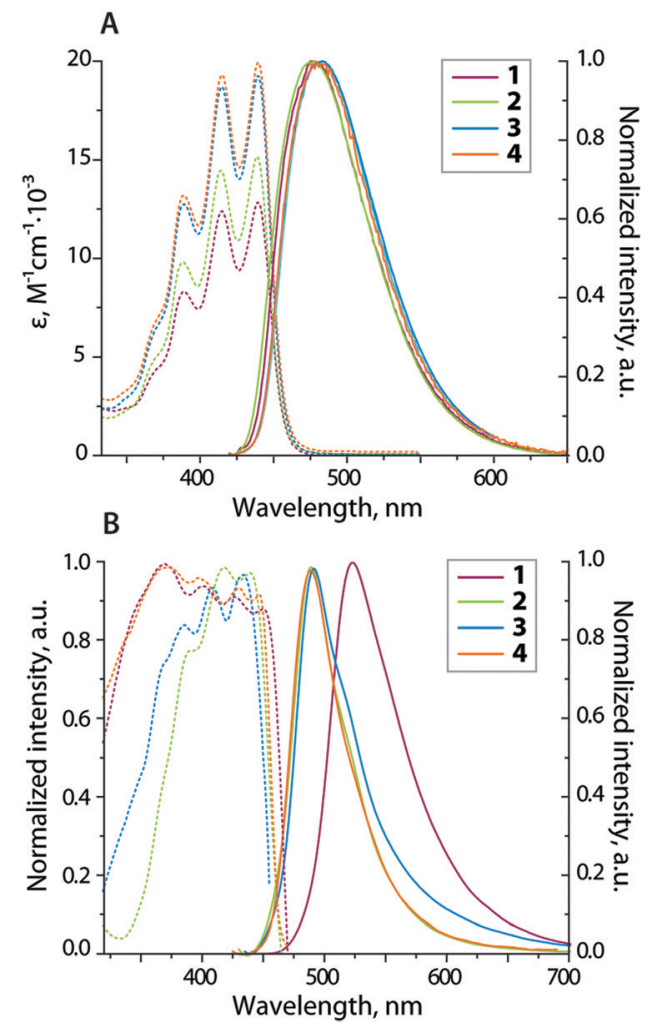

Fig. 5 (A) UV-vis absorption (dotted lines) and normalized emission (solid lines) spectra of 1-4 in $\mathrm{CH}_{2} \mathrm{Cl}_{2}\left(298 \mathrm{~K}, \lambda_{\mathrm{ex}}=415 \mathrm{~nm}\right)$; (B) normalized solidstate excitation (dotted lines) and emission (solid lines) spectra of 1-4 (298 K, $\left.\lambda_{\mathrm{ex}}=415 \mathrm{~nm}\right)$.
(370-470 nm) vibronically structured absorption bands can be assigned to the $\pi-\pi^{*}$ transitions localized within anthracene rings, though some contribution from $\sigma(\mathrm{Au}-\mathrm{P}) \rightarrow \pi^{*}$ to the $\mathrm{LE}$ absorptions cannot be excluded. ${ }^{20}$

Complexes 1-4 are luminescent in solution at room temperature (Fig. 5A). Their emission profiles, small Stokes shifts and lifetimes of $c a .3 \mathrm{~ns}$ fit well with the fluorescence behavior of cationic complexes $\left[\mathrm{Au}_{3}(\mathbf{L} \mathbf{1})_{3}\right]^{3+},\left[\mathrm{Au}_{4}(\mathbf{L} \mathbf{1})_{2}(\mu \text {-bipy })_{2}\right]^{4+}$ and $\left[\mathrm{Au}_{4}(\mathbf{L} \mathbf{1})-\right.$ (diethyldithiocarbamate) $\left.]_{3}\right]^{+, 4 a, 19 b, 21}$ and of the oxide derivative $\mathrm{O}=\mathbf{L 1} .^{22}$ Thus, the observed emission of 1-4 has mainly an intraphosphine character $\left({ }^{1} \mathrm{IL}\right)$ and is virtually independent of the nature of ancillary ligands. The unstructured fluorescence signals for these complexes, which are red shifted in comparison to that of the parent anthracene, point to some charge transfer contribution to the emissive excited state due to the presence of coordinated $\mathrm{PPh}_{2}$ groups. The luminescence quantum yields of a few percent for 1-4 can only be attributed to the gold-induced heavy atom effect that facilitates fast ISC and leads to the population of the dark triplet state. Furthermore, larger rates of $S_{1} \rightarrow T_{1}$ transition are known to increase the radiationless internal conversion $\mathrm{S}_{1} \rightarrow \mathrm{S}_{0}{ }^{10 e}$

The emission and excitation characteristics of $\mathbf{2 - 4}$ at room temperature in the solid state resemble those measured in solution (Fig. 5B). The emission band maxima are slightly red shifted with respect to the fluid medium, whereas the quantum yield decreases considerably pointing to the effective aggregation-caused quenching effect, which often operates for organic luminophores.

In contrast to 2-4, complex 1 displays an $c a$. $40 \mathrm{~nm}$ bathochromic shift of luminescence in the solid state, that is presumably determined by the dimeric structure and $\pi$-stacking of the anthracene chromophores, see Fig. 1. These intermolecular interactions apparently increase the ground state energy and decrease the energy gap between the $S_{0}$ and $S_{1}$ states. For all complexes of this group, the excited state lifetimes fall in the nanosecond domain that confirms the singlet origin of emission.

At $77 \mathrm{~K}$ the emission bands of 2-4 exhibit vibronic progressions of $c a .1000-1200 \mathrm{~cm}^{-1}$ without a substantial shift of the band center that clearly points to intraligand $\mathbf{L} \mathbf{1}$ origin of fluorescence (Fig. S4A, ESI $\dagger$ ). The broad emission of 1 at $77 \mathrm{~K}$ suggests that more than one excited state operate upon cooling. This features evidently the crystal packing effect, i.e. the influence of $\pi$-stacking and metal-metal interactions, as the spectrum of 1 in frozen solution $\left(\mathrm{CH}_{2} \mathrm{Cl}_{2}\right)$ resembles those of 2-4 (Fig. S4B, ESI $\dagger$ ).

Complexes 5-8 and 9-12. Table 2 summarizes the photophysical data for the series 5-8 and 9-12, the relevant solution and solid-state spectra are presented in Fig. 6, Fig. S5 and S6 (ESI†). Changing the 9,10-anthracene backbone in the diphosphine ligand for 1,4-naphthalene (L2-based complexes 5-8) or 2,6-naphthalene (L3-based complexes 9-12) leads to the essential variation of the photophysical behavior of the resulting gold(I) alkynyl complexes.

In solution, complexes 5-8 and 9-12 display dual emission, which comprises the $\mathrm{HE}$ band centered at $c a .350 \mathrm{~nm}$ and a structured LE band with wavelength above $500 \mathrm{~nm}$. The vibronic progression of the LE band at $c a .1300-1500 \mathrm{~cm}^{-1}$ is normal for the gold-bound aromatic chromophores ${ }^{9 b, 23}$ and therefore points to a ligand centered (L2 naphthalene backbone) nature of 
Table 1 Photophysical properties of complexes 1-4

\begin{tabular}{|c|c|c|c|c|c|c|c|}
\hline & \multicolumn{4}{|l|}{ Solution $\left(\mathrm{CH}_{2} \mathrm{Cl}_{2}, 298 \mathrm{~K}\right)$} & \multicolumn{3}{|l|}{$\underline{\text { Solid }}$} \\
\hline & $\lambda_{\mathrm{abs}}, \mathrm{nm}\left(\varepsilon \times 10^{-3}, \mathrm{~cm}^{-1} \mathrm{M}^{-1}\right)$ & $\lambda_{\mathrm{em}},{ }^{a} \mathrm{~nm}$ & $\Phi_{\mathrm{em}},{ }^{b} \%$ & $\tau_{\text {obs }}, \mathrm{ns}$ & $\lambda_{\mathrm{em}},{ }^{a} \mathrm{~nm} 298 \mathrm{~K}$ & $\lambda_{\mathrm{em}},{ }^{a} \mathrm{~nm} 77 \mathrm{~K}$ & $\Phi_{\mathrm{em}},{ }^{c} \%$ \\
\hline L1 & $277,355 \mathrm{sh}, 374,396,419$ & & & & & & \\
\hline 2 & $271(63), 367 \operatorname{sh}(5), 389(10), 415(15), 440(15)$ & 475 & 4 & 3 & 489 & $467,490,506 \mathrm{sh}$ & $<1$ \\
\hline 3 & 271 (80), 366 (6), 388 (13), 415 (19), 439 (20) & 480 & 5 & 3 & 492 & $464,488,522 \mathrm{sh}$ & $<1$ \\
\hline 4 & 270 (83), $366(6), 389(13), 415(20), 439$ (20) & 480 & 4 & 3.2 & 489 & $477,508,545 \mathrm{sh}$ & $<1$ \\
\hline
\end{tabular}

Table 2 Photophysical properties of complexes 5-12

\begin{tabular}{|c|c|c|c|c|c|c|}
\hline & \multicolumn{3}{|l|}{$\underline{\text { Solution }\left(\mathrm{CH}_{2} \mathrm{Cl}_{2}, 298 \mathrm{~K}\right)}$} & \multicolumn{3}{|l|}{$\underline{\text { Solid }}$} \\
\hline & $\lambda_{\mathrm{abs}}, \mathrm{nm}\left(\varepsilon \times 10^{-3}, \mathrm{~cm}^{-1} \mathrm{M}^{-1}\right)$ & $\lambda_{\mathrm{em}},{ }^{a} \mathrm{~nm}$ & $\lambda_{\mathrm{em}},{ }^{b} \mathrm{~nm} 298 \mathrm{~K}$ & $\lambda_{\mathrm{em}},{ }^{b} \mathrm{~nm} 77 \mathrm{~K}$ & $\tau_{\mathrm{av},}{ }^{c} \mu \mathrm{s}$ & $\Phi_{\mathrm{em}},{ }^{d} \%$ \\
\hline L2 & $274(6), 332(6)$ & & & & & \\
\hline 5 & $\begin{array}{l}268(32.5), 280(32), 296 \mathrm{sh}(19), 310(15) \text {, } \\
326(10)\end{array}$ & $350,503,538,580$ & $506,536,582$ & $511,524,540,590 \mathrm{sh}$ & 13.2 & 2 \\
\hline 6 & 275 (7), 297 (10), $310(11), 326(8.5)$ & $351,501,536,583$ & 497, 509sh, 536, 580, 632 & $497,510,535,549,576$ & 2.4 & $<1$ \\
\hline 7 & 274 (6.5), 297 (9.5), 310 (11), 326 (7) & $351,501,536,586$ & $510,536,580 \mathrm{sh}$ & $516,533,550$ & 2.1 & $<1$ \\
\hline 8 & $273(7), 297(10), 310(11), 326(8.5)$ & $352,502,540,582$ & $498,510,536,578,630$ & $514,523 \mathrm{sh}, 553,600$ & 86.3 & $<1$ \\
\hline $\mathbf{L} 3$ & $270(17), 310(9)$ & & & & & \\
\hline 9 & $\begin{array}{l}258(72), 283(46), 293(33), 310(15), \\
320(2.3), 336(2)\end{array}$ & $341,356,516,555,600$ & $478,520 \mathrm{sh}, 557,605 \mathrm{sh}$ & $488,524,555,605 \mathrm{sh}$ & 225.9 & $<1$ \\
\hline 10 & $\begin{array}{l}258(72), 275(19), 288(16), 298(11), \\
320(2.3), 336(2)\end{array}$ & $\begin{array}{l}340,356,373,514,555 \\
604\end{array}$ & $475,521,554,605,664 \mathrm{sh}$ & $486 \mathrm{sh}, 519,552,600 \mathrm{sh}$ & 205.9 & 2 \\
\hline 11 & $\begin{array}{l}258(72), 275(19), 288(16), 298(11), \\
320(2.3), 336(2)\end{array}$ & $341,356,514,555,603$ & $513,551,597,654$ & $507,546,592,647$ & 1694.4 & 5 \\
\hline 12 & $\begin{array}{l}258(72), 275(19), 288(16), 298(11) \\
320(2.3), 336(2)\end{array}$ & $342,357,517,557,603$ & $509,548,593,648$ & $504,515,543,589,645$ & 1407.4 & 7 \\
\hline
\end{tabular}

${ }^{a} \lambda_{\mathrm{ex}}=310 \mathrm{~nm}$ for $\mathbf{5 - 8}$ and $300 \mathrm{~nm}$ for $\mathbf{9 - 1 2} \cdot{ }^{b} \lambda_{\mathrm{ex}}=330 \mathrm{~nm} .{ }^{c}$ Average emission lifetimes for the two-exponential decay determined using the equation $\tau_{\mathrm{av}}=\left(A_{1} \tau_{1}{ }^{2}+A_{2} \tau_{2}{ }^{2}\right) /\left(A_{1} \tau_{1}+A_{2} \tau_{2}\right)$, where $A_{i}$ is the weight of the $i$-exponent. ${ }^{d}$ In $\mathrm{KPF}_{6}$ tablet.

this emission. A large Stokes shift together with oxygen quenching of the LE signal as depicted in Fig. 5, is indicative of the triplet origin of this band (phosphorescence), while the HE one, which also shows vibronic structures for 9-12 series $\left(\Delta \nu \sim 1200 \mathrm{~cm}^{-1}\right)$ and is not sensitive to the presence of molecular oxygen, is associated with the intraligand fluorescence of $\mathbf{L} 2$ (5-8) and $\mathbf{L 3}$ (9-12) diphosphines, visibly perturbed for $\mathbf{5}-\mathbf{8}$ by the $-\mathrm{PPh}_{2} \mathrm{AuR}$ motifs. Unfortunately, the low intensity of luminescence $\left(\Phi_{\mathrm{em}}<0.1 \%\right)$ did not allow the accurate determination of the lifetimes of singlet and triplet excited states to confirm their multiplicities.

The positions of the emission maxima are very similar within each group of complexes and the spectra are only different in relative intensities of HE fluorescence and LE phosphorescence bands (Fig. 6). The invariance of the emission energies and thus of the lowest lying excited states $\left(\mathrm{S}_{1}\right.$ and $\left.\mathrm{T}_{1}\right)$ is in line with the poor involvement of the alkynyl ligands in their composition. However, as we have shown earlier, the ancillary $-\mathrm{C}_{2} \mathrm{R}$ groups are capable of affecting the rate of intersystem crossing $\mathrm{S}_{1} \rightarrow \mathrm{T}_{n}(n \geq 1)$, altering the contribution of MLCT/ $\mathrm{L}^{\prime} \mathrm{LCT}$ transitions. ${ }^{13}$ The non-innocent role of alkynyl ligands in populating the $\mathrm{T}_{1}$ state is also seen for 5-8 and 9-12 (see the excitation spectra in Fig. S5, ESI $\dagger$ ), in which phenylalkynyl complexes 5 and $\mathbf{9}$ show the largest phosphorescence $v s$. fluorescence ratio within each series.
It is worth comparing the photophysical performance of 5-12 with that of the structurally related complexes of isomeric 1,8-bis(diphenylphosphino)naphthalene studied by Yam. ${ }^{20}$ In the latter case, the close disposition of the phosphorus substituents on the naphthalene backbone results in a virtually complete suppression of the singlet emission in solution to give phosphorescence in a red region $\left(\lambda_{\mathrm{em}}>700 \mathrm{~nm}\right)$ and microsecond lifetimes. These emission characteristics drastically differ from those of 5-12 and illustrate the effect of substitutional isomerism of the diphosphines (i.e. 1,4-naphthalene (L2), 2,6-naphthalene (L3) and 1,8-naphthalene ${ }^{20}$ ) in the modulation of the lowest lying excited state.

In the solid state, the luminescence efficiency of 5-8 and 9-12 series is enhanced compared to that in solution, and the quantum yields fall in the range of 1-7\% (Table 2). All complexes of these groups both at room temperature and at $77 \mathrm{~K}$ display structured LE bands with line shapes, which resemble the profiles of the phosphorescence profiles revealed in solution (Fig. S6, ESI†). The long lifetimes (2.1-86.3 $\mu$ s for 5-8 and 206-1694 $\mu$ s for 9-12) imply that only triplet emission retains in solids.

Complexes 13-16, 17-19 and 20-22. It has been shown earlier that gold complexes composed of the diphosphines with diethynyphenylene spacers, $\mathrm{Ph}_{2} \mathrm{P}-\mathrm{C}_{2}-\left(\mathrm{C}_{6} \mathrm{H}_{4}\right)_{n}-\mathrm{C}_{2}-\mathrm{PPh}_{2}$, often exhibit higher quantum efficiencies than their counterparts composed of the ligands with phenylene backbones $\mathrm{Ph}_{2} \mathrm{P}-\left(\mathrm{C}_{6} \mathrm{H}_{4}\right)_{n}-\mathrm{PPh}_{2}{ }^{6 a, 24}$ 

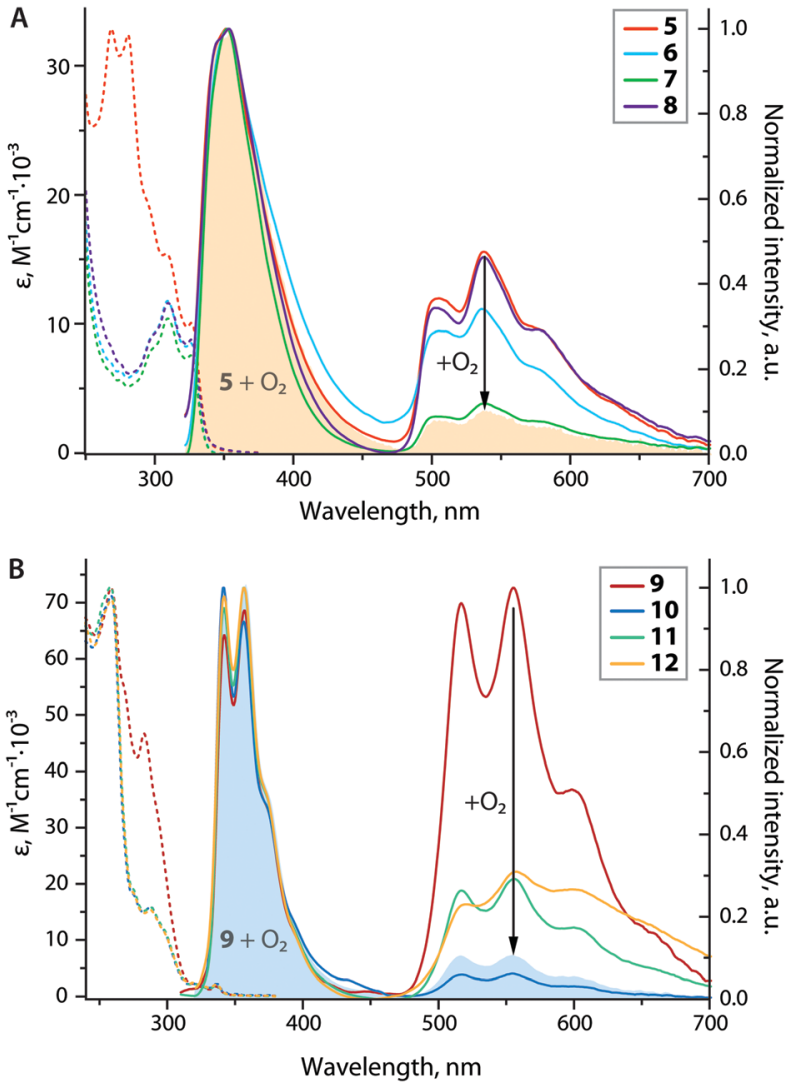

Fig. 6 Room temperature UV-vis absorption (dotted lines) and normalized emission (solid lines) spectra of 5-8 $\left(\mathrm{A}, \lambda_{\mathrm{ex}}=310 \mathrm{~nm}\right)$ and 9-12 ( $\mathrm{B}, \lambda_{\mathrm{ex}}=300 \mathrm{~nm}$ ) in degassed $\mathrm{CH}_{2} \mathrm{Cl}_{2}$; color-filled profiles correspond to the spectra of $\mathbf{5}$ (peach, A) and $\mathbf{9}$ (blue, B) in aerated solutions.

Therefore, the low emission intensities of compounds 1-12, which contain $\mathrm{PPh}_{2}$-functionalized $\mathrm{PAH}$ moieties, prompted us to investigate the photophysical characteristics of congener complexes 13-22 bearing ethynyl-modified ligands L4-L6. Simultaneously, within these series we have systematically altered the electronic properties of auxiliary phenylacetylene groups $-\mathrm{C}_{2} \mathrm{C}_{6} \mathrm{H}_{4}-\mathrm{X}\left(\mathrm{X}=\mathrm{CF}_{3}, \mathrm{H}, \mathrm{OMe}\right.$, $\mathrm{NMe}_{2}$ ) to inspect their influence on the optical behavior of intraphosphine $\mathrm{PAH}$ chromophores.

Complexes $\left(\mathrm{AuC}_{2} \mathrm{C}_{6} \mathrm{H}_{4} \mathrm{X}\right)_{2} \mathbf{L 4}\left(\mathrm{X}=\mathrm{H}, 13 ; \mathrm{CF}_{3}, 14 ; \mathrm{OMe}, 15\right.$; and $\left.\mathrm{NMe}_{2}, 16\right)$ with diethynyl-anthracene phosphine show absorption spectra, which are mainly derived from that of the free ligand $\mathbf{L 4}$ (Table 3 and Fig. 7). In addition to the absorption bands of the phosphines, complexes 13-16 display moderately intense absorption shoulders in the range of $286-311 \mathrm{~nm}$, which can be attributed to $\mathrm{C} \equiv \mathrm{CR}$ intraligand transitions. The emission profiles for 13-16 are nearly the same irrespective of the $\mathrm{C} \equiv \mathrm{CR}$ ligand and also match the spectra of $\left(\mathrm{PR}_{3} \mathrm{Au}\right)_{2}$ (9,10-diethynylanthracene) complexes meaning that the PAH core of $\mathbf{L} \mathbf{4}$ determines the luminescence properties. ${ }^{20,25}$ The structured signals, high intensity ( $\Phi_{\mathrm{em}}=87 \%$ and $93 \%$ for 13 and 14) and nanosecond lifetimes prove the ${ }^{1} \mathrm{IL}$ (anthracene) nature of the excited state. The excitation spectra of 13-16 (Fig. 7B) are essentially similar to the absorption spectrum of L4, meaning that $\mathrm{LL}^{\prime}\left(\pi \mathrm{C}_{2} \mathrm{R} \rightarrow \pi^{*} \mathbf{L 4}\right) / \mathrm{ML}\left(\mathrm{Au} \mathrm{d}_{\pi} \rightarrow \pi^{*} \mathbf{L 4}\right)$ charge transfers play a minor role in the lowest lying excited state $S_{1}$. Despite the fact that the modulation of the electron donating ability of $-\mathrm{C}_{2} \mathrm{C}_{6} \mathrm{H}_{4} \mathrm{X}$ alkynyl ligands does not change the shape $14\left(\mathrm{X}=\mathrm{CF}_{3}\right)$ is the most intense fluorophore among the studied compounds $\left(\Phi_{\mathrm{em}}=93 \%\right)$, gradually increasing the basicity of $\mathrm{X}$ substituents leads to a drastic drop of the quantum yield for $16\left(\mathrm{X}=\mathrm{NMe}_{2}, \Phi_{\mathrm{em}}=1 \%\right)$. A similar trend was observed for $\mathrm{Au}(\mathrm{I})$ complexes with oligophenylene $\pi$-chromophores, for which, however, changing $\mathrm{X}=\mathrm{CF}_{3}$ for OMe primarily enhances phosphorescence $v s$. fluorescence emission. ${ }^{13}$ To gain additional experimental proof that alkynyl ligands can govern the radiationless decay pathways, the photophysics of complex $\mathbf{1 6}$ has been studied in the presence of trifluoroacetic acid. Indeed, protonation of the $\mathrm{NMe}_{2}$ group results in an ca. 35-fold increase of luminescence intensity (Table 3 and Fig. 7C) and disappearance of the $\sim 300 \mathrm{~nm}$ absorption band assigned to $\mathrm{C}_{2} \mathrm{C}_{6} \mathrm{H}_{4} \mathrm{NMe}_{2}$ localized transitions. The latter evidently shifts to higher energies due to stabilization of the alkynyl-aniline $\pi$ orbitals caused by switching the electron-rich $\mathrm{NMe}_{2}$ function to the electron deficient $\mathrm{NMe}_{2} \mathrm{H}^{+}$ammonium derivative. ${ }^{26}$

The solid-state emissions of complexes 13-15 are substantially red shifted (ca. $75 \mathrm{~nm}$ ) with respect to their solution spectra (Fig. S7, ESI $\dagger$ ), and $\mathbf{1 6}$ is not luminescent. Additionally, the loss of the vibronic structure, dramatically lower intensity ( $\Phi_{\mathrm{em}}$ up to $5 \%$ for 14 ) and short emission lifetimes of several nanoseconds evidence fluorescence, probably arising from intermolecular charge transfer between the PAH chromophores, which tend to aggregate in the solid state.

The photophysical data for the series 17-19 and 20-22 with 1,4- and 2,6-diethynylnaphthalene emitting centers, respectively,

Table 3 Photophysical properties of complexes 13-16

\begin{tabular}{|c|c|c|c|c|c|c|c|c|}
\hline & \multicolumn{4}{|l|}{ Solution $\left(\mathrm{CH}_{2} \mathrm{Cl}_{2}, 298 \mathrm{~K}\right)$} & \multicolumn{4}{|l|}{ Solid } \\
\hline & $\lambda_{\mathrm{abs}}, \mathrm{nm}\left(\varepsilon \times 10^{-3}, \mathrm{~cm}^{-1} \mathrm{M}^{-1}\right)$ & $\lambda_{\mathrm{em}}{ }^{a} \mathrm{~nm}$ & $\Phi_{\mathrm{em}}, \%$ & $\tau_{\text {obs }}, \mathrm{ns}$ & $\begin{array}{l}\lambda_{\mathrm{em}}, b \mathrm{~nm} \\
298 \mathrm{~K}\end{array}$ & $\begin{array}{l}\lambda_{\mathrm{em}}, b \mathrm{~nm} \\
77 \mathrm{~K}\end{array}$ & $\Phi_{\mathrm{em}}, \%$ & $\begin{array}{l}\tau_{\text {obs }} \\
\text { ns }\end{array}$ \\
\hline L4 & $273,381,406,430,458$ & - & - & - & - & & - & - \\
\hline 13 & 270 (103), 363 (3), 382 (7), 407 (12), 431 (28), 460 (39) & $465,495,530$ & 87 & 4.2 & 541 & $530,575 \mathrm{sh}$ & 4 & 3.8 \\
\hline 14 & $271(106), 286(53), 363(2), 382(7), 407$ (11), $431(27), 460$ (39) & $465,495,530$ & 93 & 4.4 & 535 & 516,555 & 5 & 5.5 \\
\hline 15 & $270(106), 286 \mathrm{sh}(56), 363(5), 382(9), 407$ (14), 431 (31), 460 (44) & $465,495,530$ & 2 & 4.2 & 541 & 525,562 & 1 & 11.8 \\
\hline 16 & $\begin{array}{l}271 \text { (104), 289sh (53), } 311(46), 363 \text { (7), } 382(10), 407 \text { (15), } \\
431(33), 460(46)\end{array}$ & $465,495,530$ & 1 & 4.0 & - & & - & - \\
\hline $16 \mathbf{H}^{+c}$ & $271(105), 384(9), 408(12), 433(26), 461(36)$ & $465,495,530$ & 39 & 4.7 & - & & - & - \\
\hline
\end{tabular}

${ }^{a} \lambda_{\mathrm{ex}}=430 \mathrm{~nm} .{ }^{b} \lambda_{\mathrm{ex}}=350 \mathrm{~nm} .{ }^{c} 16$ in the presence of $0.1 \mathrm{M} \mathrm{CF}_{3} \mathrm{COOH}$ in $\mathrm{CH}_{2} \mathrm{Cl}_{2}$. 

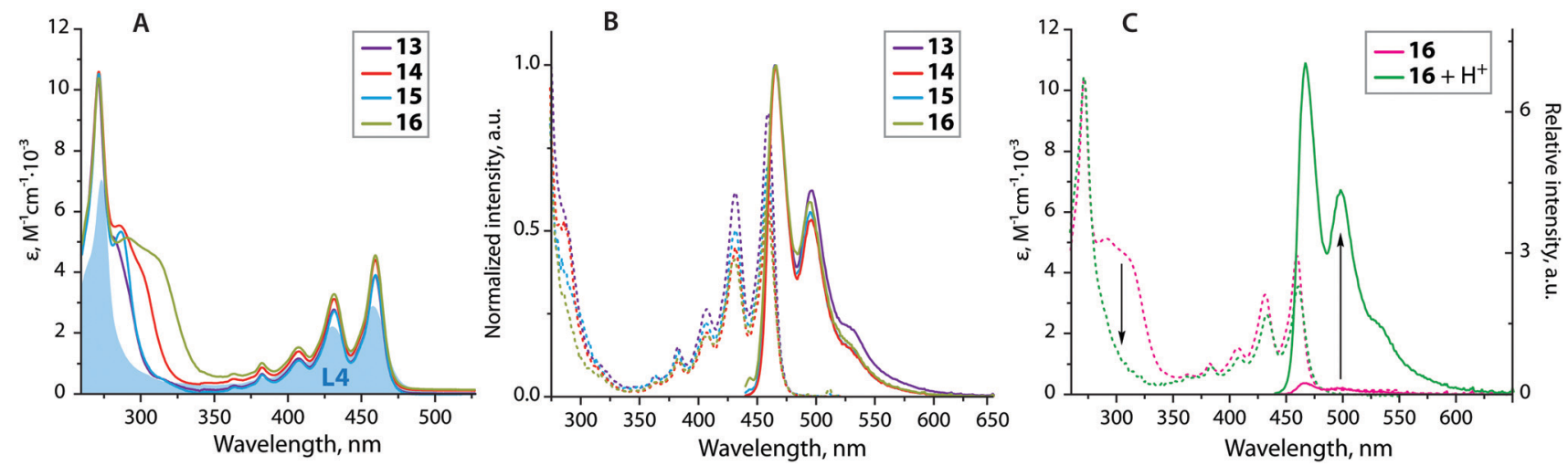

Fig. 7 (A) UV-vis absorption spectra of 13-16, color-filled profile corresponds to $\mathbf{L} 4\left(\mathrm{CH}_{2} \mathrm{Cl}_{2}, 298 \mathrm{~K}\right.$ ); (B) normalized excitation (dotted lines) and emission (solid lines) spectra of $13-16\left(\mathrm{CH}_{2} \mathrm{Cl}_{2}, 298 \mathrm{~K}\right)$; and $(\mathrm{C})$ changes in absorption and emission spectra of 16 upon protonation by $\mathrm{CF}_{3} \mathrm{COOH}$.

Table 4 Photophysical properties of complexes 17-22

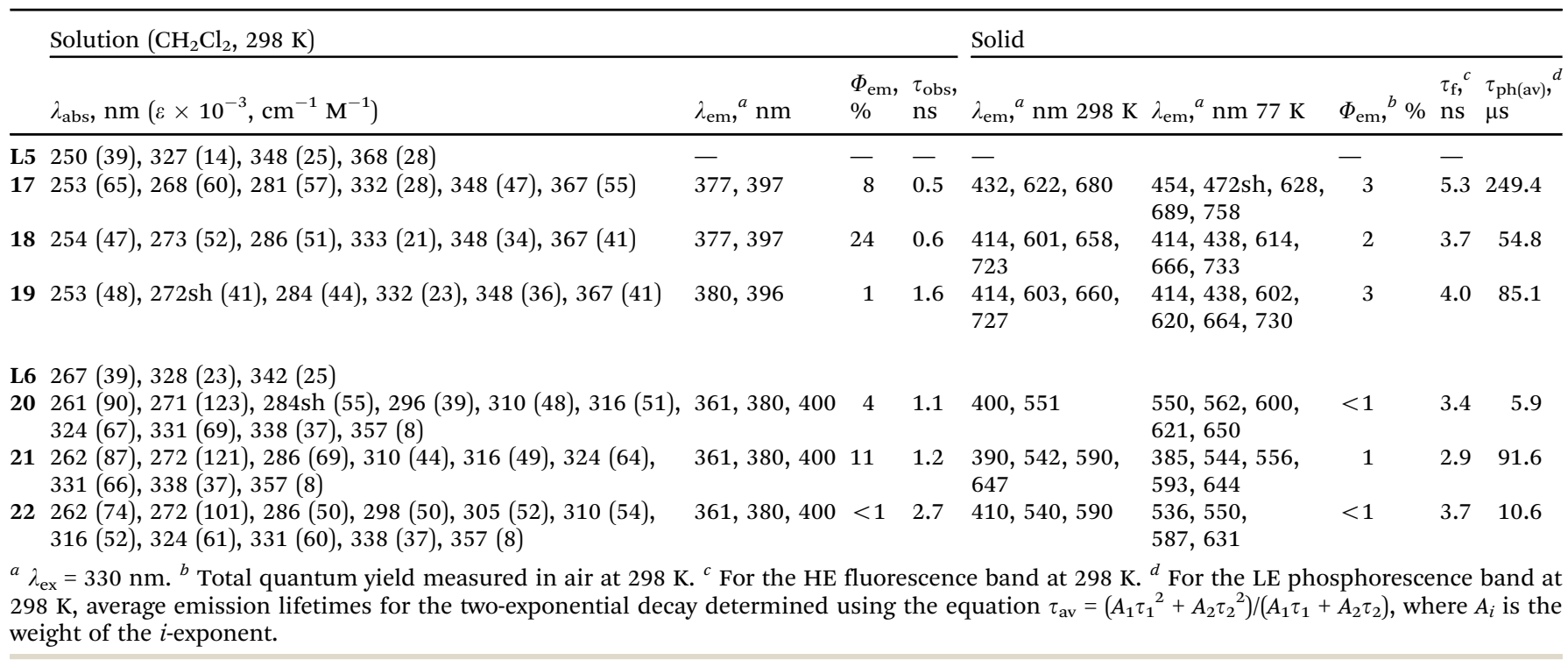

are listed in Table 4. In solution both groups of complexes reveal singlet emission HE signals in the deep blue to violet region with maximum quantum yields reached by $\mathrm{CF}_{3}$-substituted alkynyl species $18\left(\Phi_{\mathrm{em}}=24 \%\right)$ and $21\left(\Phi_{\mathrm{em}}=11 \%\right)$. Analogously to the anthracene-based family 13-16 described above, the naphthalene compounds 17-22 manifest a steep dependence of fluorescence intensity on the electron richness of the alkynyl ligands, which do not affect the energies of the bands (Fig. 8).

In the solid state, complexes 17-22 behave differently than in solution and display two emission bands, which are particularly pronounced for $\mathrm{CF}_{3}$-containing compounds 18 and 21 (Fig. 8C, Fig. S8 and S9, ESI $\dagger$ ). The broadened unresolved HE signals, which have the lifetimes of few nanoseconds, are red shifted for $c a .30 \mathrm{~nm}$ with respect to the corresponding fluorescence bands in solution. The intensity of long-lived LE emissions $\left(\lambda_{\mathrm{em}}>600 \mathrm{~nm}\right.$ for 17-19 and $>540$ for 20-22) is readily reduced in air, the extent of quenching is supposedly dependent on the morphology of the solid sample and is facilitated by its intrinsic porosity. ${ }^{13}$ Notably, the Commission Internationale de l'Eclairage (CIE) coordinates of compound 21 in the solid state (Table S3, ESI $\dagger$ ) correspond to nearly pure white color $(0.32,0.32)$. The fluorescence $v s$. phosphorescence ratio for 17-19 at $298 \mathrm{~K}$ can be correlated with the donicity of alkynyl ligands, the increase of which favors transition to the $\mathrm{T}_{1}$ state, and therefore explained in terms of variable MLCT/L'LCT contributions. ${ }^{13}$ However, triad 20-22 does not obey the given trend (Fig. S9, ESI $\dagger$ ) that testifies to the presence of subtle effects, which operate in the solid phase and have fine influence on the optical characteristics.

It is pertinent to remark the discrepancy in the emission behavior for $\mathbf{1 7}$ and $\mathbf{2 0}$ and of their aryl relatives 5 and $\mathbf{9}$ bearing the same phenyl alkynyl ligands. The latter complexes are dually emissive in solution, but in the solid state demonstrate pure phosphorescence. In a simplified approach, the difference in inducing triplet luminescence in 17, 20 vs. 5, 9 stems from the nature of the coordinating group, which links the chromophore $\mathrm{PAH}$ center to the gold ion and therefore determines the electronic communication and the distance between them. The smaller separation $\mathrm{PAH} \cdots \mathrm{Au}$ in $\mathbf{5}$ and $\mathbf{9}$ presumably facilitates spin-orbit coupling primarily via the heavy atom effect and 

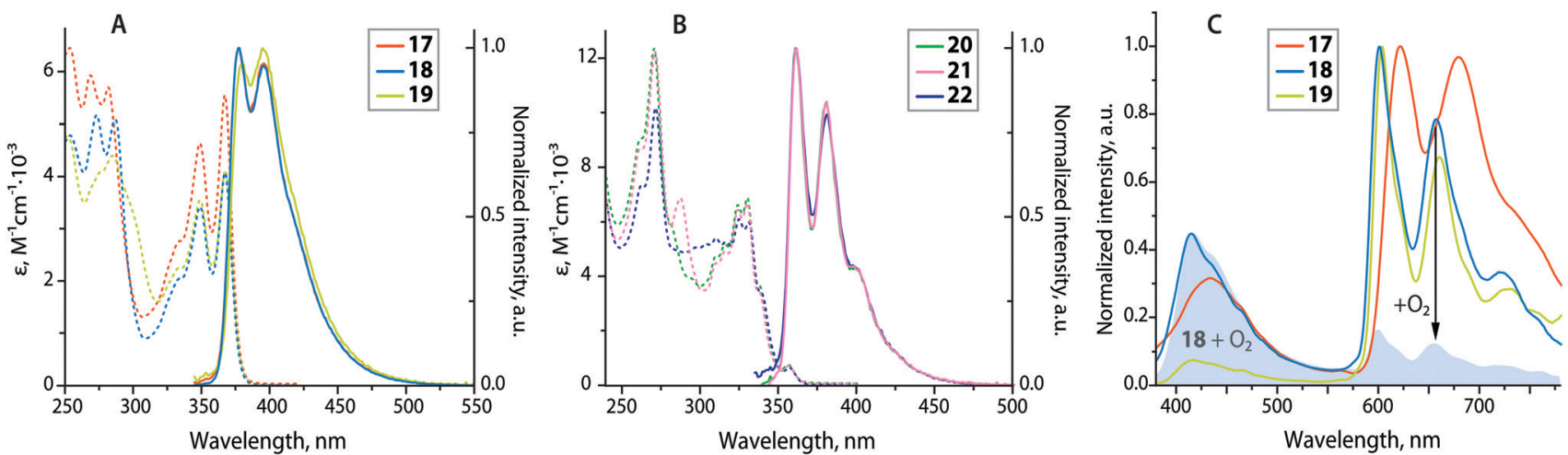

Fig. 8 Room temperature UV-vis absorption (dotted lines) and normalized emission (solid lines) spectra of 17-19 (A) and 20-22 (B) in degassed $\mathrm{CH}_{2} \mathrm{Cl}_{2}$; and (C) normalized solid-state emission spectra of 17-19 under an Ar atmosphere; the color-filled profile corresponds to the spectra of $\mathbf{1 8}$ in air.

increases the rate of intersystem crossing $\mathrm{S}_{1} \rightarrow \mathrm{T}_{n}$ so that phosphorescence starts to compete with fluorescence in fluid medium and prevails in solid samples. In line with this rationalization, the direct bonding of naphthalene to $\left\{\mathrm{AuPR}_{3}\right\}$ fragments almost completely suppresses singlet emission already in solution. ${ }^{4 c}$ In the case of 17-22 the additional ethynyl spacers of the diphosphine backbones increase both the PAH *Au gap and fluorescence quantum efficiency, but prevent triplet emission in solution due to poor ISC. On the other hand, for these compounds dual luminescence is attained in the solid state that provides a route to molecular materials for panchromatic light generation.

\section{Conclusions}

In this work, we have synthesized a series of luminescent dinuclear gold(I) alkynyl complexes composed of phosphinefunctionalized polyaromatic (PAH) chromophores. Systematic alteration of PAH moieties, the position and electronic features of P-donor connectivities reveal an essential influence on the optical behavior of the metal compounds. The anthracenebased gold(I) complexes 1-4 and 13-16 apparently demonstrate intraligand fluorescence localized on the diphosphine backbone with negligible contribution of the alkynyl and metal d orbitals to the emissive excited state. An extension of the PAH spacer (anthracene $\rightarrow$ diethynylanthracene) appears to be an efficient tool for increasing the quantum yield in solution; compounds 1-4 show $\Phi_{\mathrm{em}}$ up to 5\%, whereas for 13-16 $\Phi_{\mathrm{em}}$ reaches $93 \%$. Increasing the basicity of substituents $\mathrm{X}$ in alkynyl ligands $-\mathrm{C}_{2} \mathrm{C}_{6} \mathrm{H}_{4} \mathrm{X}$ leads to a drastic drop of the emission intensity $\left(\mathrm{X}=\mathrm{CF}_{3}, \Phi_{\mathrm{em}}=93 \% \rightarrow \mathrm{X}=\mathrm{NMe}_{2}, \Phi_{\mathrm{em}}=1 \%\right)$ complexes 13-16. The replacement of the anthracene motif for the naphthalene core produces distinct dual emission in solution for $\mathbf{L} \mathbf{2}$ and $\mathbf{L 3}$-based complexes 5-12. Their luminescence profiles comprise the high-energy fluorescence band centered at $c a .350 \mathrm{~nm}$ and a vibronically structured phosphorescence signal with the wavelength maxima above $500 \mathrm{~nm}$. In the solid state, the fluorescence signals for these species are completely suppressed and only triplet emission is observed. In contrast to $\mathbf{5 - 1 2}$, their ethynyl-phosphine congeners 17-22 ( $\mathbf{L} \mathbf{4}$ and $\mathbf{L 5}$-based compounds) in solution exhibit only structured HE fluorescence, as manifested by nanosecond lifetimes of the excited state, with maximum quantum yields attained for $18\left(\Phi_{\mathrm{em}}=24 \%\right)$ and $21\left(\Phi_{\mathrm{em}}=11 \%\right)$ with $\mathrm{CF}_{3}$-substituted alkynyl groups. However, as solid powders complexes 17-22 are dually luminescent at room temperature. This effect is tentatively ascribed to the influence of ethynyl fragments between the phosphorus atoms and the $\pi$-spacers, which increase the PAH $\cdots$ Au distance and consequently diminish spin-orbit coupling, resulting in radiative relaxation of both $S_{1}$ and $\mathrm{T}_{1}$ states only in the solid state.

\section{Conflicts of interest}

There are no conflicts to declare.

\section{Acknowledgements}

Financial support from the Academy of Finland (grant 317903, I. O. K.) and Russian Science Foundation (spectral characterization and photophysical studies, grant 19-13-00132, S. P. T.) is gratefully acknowledged. This work was performed using the equipment of the Analytical Centre for Nano- and Biotechnologies (Peter the Great St. Petersburg Polytechnic University with financial support from the Ministry of Education and Science of Russian Federation) and Centers for Magnetic Resonance, for Optical and Laser Materials Research, for Chemical Analysis and Materials Research, Research Park of St. Petersburg State University.

\section{References}

1 (a) C. Reichardt, Chem. Rev., 1994, 94, 2319-2358; (b) N. Siraj, B. El-Zahab, S. Hamdan, T. E. Karam, L. H. Haber, M. Li, S. O. Fakayode, S. Das, B. Valle, R. M. Strongin, G. Patonay, H. O. Sintim, G. A. Baker, A. Powe, M. Lowry, J. O. Karolin, C. D. Geddes and I. M. Warner, Anal. Chem., 2016, 88, 170-202. 2 (a) X.-K. Chen, D. Kim and J.-L. Brédas, Acc. Chem. Res., 2018, 51, 2215-2224; (b) S.-C. Lee, J. Heo, H. C. Woo, J.-A. Lee, Y. H. Seo, C.-L. Lee, S. Kim and O. P. Kwon, Chem. Eur. J., 2018, 24, 13706-13718; (c) L. Wang, M. S. Frei, A. Salim and K. Johnsson, J. Am. Chem. Soc., 2019, 141, 2770-2781. 
3 (a) Y. Y. Chia and M. G. Tay, Dalton Trans., 2014, 43, 13159-13168; (b) H. Xu, R. Chen, Q. Sun, W. Lai, Q. Su, W. Huang and X. Liu, Chem. Soc. Rev., 2014, 43, 3259-3302; (c) F. N. Castellano, Acc. Chem. Res., 2015, 48, 828-839; (d) V. W.-W. Yam, V. K.-M. Au and S. Y.-L. Leung, Chem. Rev., 2015, 115, 7589-7728.

4 (a) J. H. K. Yip and J. Prabhavathy, Angew. Chem., Int. Ed., 2001, 40, 2159-2162; (b) V. W.-W. Yam, K.-L. Cheung, S.-K. Yip and N. Zhu, Photochem. Photobiol. Sci., 2005, 4, 149-153; (c) L. Gao, M. A. Peay, D. V. Partyka, J. B. Updegraff, T. S. Teets, A. J. Esswein, M. Zeller, A. D. Hunter and T. G. Gray, Organometallics, 2009, 28, 5669-5681; (d) M.-H. Nguyen and J. H. K. Yip, Organometallics, 2010, 29, 2422-2429; (e) L. Gao, D. S. Niedzwiecki, N. Deligonul, M. Zeller, A. D. Hunter and T. G. Gray, Chem. - Eur. J., 2012, 18, 6316-6327; (f) S. Goswami, R. W. Winkel and K. S. Schanze, Inorg. Chem., 2015, 54, 10007-10014; (g) A. M. Christianson and F. P. Gabbaï, Inorg. Chem., 2016, 55, 5828-5835; (h) J. R. Shakirova, O. A. Tomashenko, E. V. Grachova, G. L. Starova, V. V. Sizov, A. F. Khlebnikov and S. P. Tunik, Eur. J. Inorg. Chem., 2017, 4180-4186; (i) A. Gutiérrez-Blanco, V. Fernández-Moreira, M. C. Gimeno, E. Peris and M. Poyatos, Organometallics, 2018, 37, 1795-1800.

5 (a) J. C. Lima and L. Rodriguez, Chem. Soc. Rev., 2011, 40, 5442-5456; (b) Y. Liu, H. Guo and J. Zhao, Chem. Commun., 2011, 47, 11471-11473; (c) T. Yoshihara, Y. Yamaguchi, M. Hosaka, T. Takeuchi and S. Tobita, Angew. Chem., Int. Ed., 2012, 51, 4148-4151; (d) T. Yoshihara, Y. Yamaguchi, M. Hosaka, T. Takeuchi and S. Tobita, Angew. Chem., Int. Ed., 2012, 51, 4148-4151; (e) P. W. Zach, S. A. Freunberger, I. Klimant and S. M. Borisov, ACS Appl. Mater. Interfaces, 2017, 9, 38008-38023.

6 (a) Y.-C. Chang, K.-C. Tang, H.-A. Pan, S.-H. Liu, I. O. Koshevoy, A. J. Karttunen, W.-Y. Hung, M.-H. Cheng and P.-T. Chou, J. Phys. Chem. C, 2013, 117, 9623-9632; (b) M. Bachmann, O. Blacque and K. Venkatesan, Chem. Eur. J., 2017, 23, 9451-9456; (c) M. Pan, W.-M. Liao, S.-Y. Yin, S.-S. Sun and C.-Y. Su, Chem. Rev., 2018, 118, 8889-8935.

7 (a) H. Shi, H. Sun, H. Yang, S. Liu, G. Jenkins, W. Feng, F. Li, Q. Zhao, B. Liu and W. Huang, Adv. Funct. Mater., 2013, 23, 3268-3276; (b) Q. Zhao, X. Zhou, T. Cao, K. Y. Zhang, L. Yang, S. Liu, H. Liang, H. Yang, F. Li and W. Huang, Chem. Sci., 2015, 6, 1825-1831; (c) F. Liu, J. Wen, S.-S. Chen and S. Sun, Chem. Commun., 2018, 54, 1371-1374.

8 H. G. Raubenheimer and H. Schmidbaur, Organometallics, 2012, 31, 2507-2522.

9 (a) W. Y. Heng, J. Hu and J. H. K. Yip, Organometallics, 2007, 26, 6760-6768; (b) D. V. Partyka, T. S. Teets, M. Zeller, J. B. Updegraff, A. D. Hunter and T. G. Gray, Chem. - Eur. J., 2012, 18, 2100-2112.

10 (a) W. Lu, W.-M. Kwok, C. Ma, C. T.-L. Chan, M.-X. Zhu and C.-M. Che, J. Am. Chem. Soc., 2011, 133, 14120-14135; (b) J. Gil-Rubio, V. Cámara, D. Bautista and J. Vicente, Organometallics, 2012, 31, 5414-5426; (c) K. T. Chan, G. S. M. Tong, W.-P. To, C. Yang, L. Du, D. L. Phillips and C.-M. Che, Chem. Sci., 2017, 8, 2352-2364; (d) M. Ferrer,
L. Giménez, A. Gutiérrez, J. C. Lima, M. Martínez, L. Rodríguez, A. Martín, R. Puttreddy and K. Rissanen, Dalton Trans., 2017, 46, 13920-13934; (e) E. Aguiló, A. J. Moro, M. Outis, J. Pina, D. Sarmento, J. S. Seixas de Melo, L. Rodríguez and J. C. Lima, Inorg. Chem., 2018, 57, 13423-13430; $(f)$ S. Wan and W. Lu, Angew. Chem., Int. Ed., 2017, 56, 1784-1788; (g) E. C. Constable, C. E. Housecroft, M. K. Kocik, M. Neuburger, S. Schaffner and J. A. Zampese, Eur. J. Inorg. Chem., 2009, 4710-4717; (h) X.-L. Li, K.-J. Zhang, J.-J. Li, X.-X. Cheng and Z.-N. Chen, Eur. J. Inorg. Chem., 2010, 3449-3457.

11 (a) T. L. Stott, M. O. Wolf and B. O. Patrick, Inorg. Chem., 2005, 44, 620-627; (b) Z. Chen, G. Liu, R. Wang and S. Pu, RSC Adv., 2017, 7, 15112-15115.

12 I. O. Koshevoy, C.-L. Lin, C.-C. Hsieh, A. J. Karttunen, M. Haukka, T. A. Pakkanen and P.-T. Chou, Dalton Trans., 2012, 41, 937-945.

13 I. Kondrasenko, K.-y. Chung, Y.-T. Chen, J. Koivistoinen, E. V. Grachova, A. J. Karttunen, P.-T. Chou and Igor O. Koshevoy, J. Phys. Chem. C, 2016, 120, 12196-12206.

14 (a) G. E. Coates and C. Parkin, J. Chem. Soc., 1962, 3220-3226; (b) I. O. Koshevoy, Y.-C. Chang, A. J. Karttunen, S. I. Selivanov, J. Jänis, M. Haukka, T. A. Pakkanen, S. P. Tunik and P.-T. Chou, Inorg. Chem., 2012, 51, 7392-7403.

15 Y.-P. Ou, C. Jiang, D. Wu, J. Xia, J. Yin, S. Jin, G.-A. Yu and S. H. Liu, Organometallics, 2010, 30, 5763-5770.

16 J. N. Demas and G. A. Crosby, J. Phys. Chem., 1971, 75, 991-1024. 17 (a) V. W.-W. Yam, S. W.-K. Choi and K.-K. Cheung, Organometallics, 1996, 15, 1734-1739; (b) M. Ferrer, A. Gutiérrez, L. Rodríguez, O. Rossell, J. C. Lima, M. Font-Bardia and X. Solans, Eur. J. Inorg. Chem., 2008, 2899-2909.

18 (a) E. R. T. Tiekink and J.-G. Kang, Coord. Chem. Rev., 2009, 253, 1627-1648; (b) H. Schmidbaur and A. Schier, Chem. Soc. Rev., 2012, 41, 370-412.

19 (a) K. Zhang, J. Prabhavathy, J. H. K. Yip, L. L. Koh, G. K. Tan and J. J. Vittal, J. Am. Chem. Soc., 2003, 125, 8452-8453; (b) R. Lin, J. H. K. Yip, K. Zhang, L. L. Koh, K.-Y. Wong and H. K. Piu, J. Am. Chem. Soc., 2004, 126, 15852-15869.

20 V. W.-W. Yam and S. W.-K. Choi, J. Chem. Soc., Dalton Trans., 1996, 4227-4232.

21 J. Li, X.-F. Zhu, L.-Y. Zhang and Z.-N. Chen, RSC Adv., 2015, 5, 34992-34998.

22 (a) Z. Fei, N. Kocher, C. J. Mohrschladt, H. Ihmels and D. Stalke, Angew. Chem., Int. Ed., 2003, 42, 783-787; (b) Y. Zhao, L. Duan, X. Zhang, D. Zhang, J. Qiao, G. Dong, L. Wang and Y. Qiu, RSC Adv., 2013, 3, 21453-21460.

23 L. Gao, D. V. Partyka, J. B. I. Updegraff, N. Deligonul and T. G. Gray, Eur. J. Inorg. Chem., 2009, 2711-2719.

24 V. F. Moreira, J. Cámara, E. S. Smirnova, I. O. Koshevoy, A. Laguna, S. P. Tunik, M. C. Blanco and M. C. Gimeno, Organometallics, 2016, 35, 1141-1150.

25 V. Mishra, A. Raghuvanshi, A. K. Saini and S. M. Mobin, J. Organomet. Chem., 2016, 813, 103-109.

26 I. O. Koshevoy, A. J. Karttunen, S. P. Tunik, J. Jänis, M. Haukka, A. S. Melnikov, P. Y. Serdobintsev and T. A. Pakkanen, Dalton Trans., 2010, 39, 2676-2683. 